\title{
Fish oils and human diet
}

\author{
BY J. R. SARGENT \\ NERC Unit of Aquatic Biochemistry, Department of Biological and Molecular Sciences, \\ University of Stirling, Stirling FK9 $4 L A$
}

\begin{abstract}
Trends in global fish catches are described together with fish landings and fish consumption in the UK. The importance of $n-6$ and $n-3$ polyunsaturated fatty acids as essential constituents of human diets is considered and the role of oily fish as a dietary source of the long-chain $n-3$ polyunsaturates, docosahexaenoic acid and eicosapentaenoic acid, is emphasized. The origin of $n-3$ polyunsaturates in the marine phytoplankton and their transmission via zooplankton to fish is described as a means of understanding the composition of different fish body oils. The ease with which the fatty acid composition of fish body oils can be manipulated by altering the fatty acid composition of their feeds is emphasized and the dietary requirements of marine and freshwater fish for $n-3$ and $n-6$ polyunsaturates considered. Farming fish on diets containing principally fish meal and fish oil, as used in salmon production in Scotland, generates a high quality product with levels of long-chain $n-3$ polyunsaturates equalling or exceeding those of wild fish. Farming fish on high quality marine oils rich in docosahexaenoic and eicosapentaenoic acids is an efficient means of delivering these essential nutrients in human diets and also efficiently exploiting a strictly limited marine bioresource.
\end{abstract}

Polyunsaturated fatty acids: Eicosapentaenoic acid: Docosahexaenoic acid: Fish nutrition

\section{MARINE FISHERIES: A LIMITED, OVER-EXPLOITED AND THREATENED NATURAL RESOURCE}

There is now much public awareness of and media focus on the problems of fisheries quotas, over-fishing and the collapse of some major fisheries. The magnitude of the problem was illustrated recently by Pauly \& Christensen (1995) who estimated that, at the turn of the 1980 s, between 24 and $35 \%$ of the total primary production in those ocean areas of greatest fish production was already required to sustain international fish catches. International fisheries have now been exploited to the limits of sustainability or beyond. As James (1994) has stated, the demand for fish both nationally and internationally exceeds its availability, tempting fishermen, governments and entrepreneurs to invest in catching and processing capacities that far exceed what fisheries can sustain. Open access to fisheries and a general failure of governments and the industry to manage fisheries rationally has exaggerated the problem. It is scarcely surprising that there is now great pressure from numerous environmental groups on governments, the fishing industry, the fish processing industry and even on major retailers of fish products, to stop over-exploitation of our fisheries. Such 'ecopressure' with its direct appeal to the consumer, is a relatively new and very effective instrument for controlling fish consumption and the fisheries. It is essential, however, that such pressure is based much more on scientific knowledge and much less on emotional reaction than has been the case so far.

World fisheries increased from about 20 million tonnes in 1950 to about 100 million tonnes in 1990 and have thereafter remained steady or declined slightly (James, 1994). In 
1992, marine fisheries yielded 82.5 million tonnes, freshwater fisheries yielded 15.6 million tonnes and aquaculture, both marine and freshwater, had increased to 14 million tonnes. Aquaculture production has increased in recent decades and is projected to double by 2010 , but this will not increase total fish production because aquaculture is heavily dependent on fish meal and fish oil produced from marine fisheries. Currently $32 \%$ of the total marine catch is converted to fish meal and oil, largely from small shoaling pelagic fish such as anchovy, sardines, sprats, capelin and herring. In 1990, $14 \%$ of the world production of fish meal was used for fish feeds, $20 \%$ for pig feeds and $58 \%$ for poultry feeds. Of the total world production of fish oils in 1992, some 600000 tonnes were used in human food, mostly in margarine and cooking fats as partially hydrogenated fish oils, and some 300000 tonnes used in animal feeds (Barlow \& Pike, 1994). The use of fish oils in animal feeds has grown in recent years, mostly due to the rapid growth of salmon farming. Of the estimated 326000 tonnes of fish oil used for fish feeds in 1993, salmon and trout feeds accounted for 35 and $23 \%$ of the total respectively (Barlow \& Pike, 1994). As these authors state, human consumption of partially hydrogenated fish oils is decreasing quite rapidly, largely due to consumer preference for partially hydrogenated vegetable oils, so that it is unlikely that there will be a shortage of fish oils for animal production including farmed fish production in the foreseeable future. However, given the finite supply of fish meal, fish farming can only grow by finding practical alternatives to fish meal, which has not so far proved possible, or at the expense of poultry and pig production.

Japan, Russia, China, Chile and Peru are now the major fishing nations with the UK being a minor player. Thus, in 1991 UK fish landings totalled about 500000 tonnes ( $2 \%$ of the world total), comprising about 260000 tonnes of demersal fish, mainly cod, haddock, whiting and plaice, and 240000 tonnes of pelagic fish, mainly mackerel and herring, with shellfish landings being very small at 22000 tonnes (British Nutrition Foundation, 1993). Neither is the UK a major consumer of fish. Thus, the average consumption of fish in the UK in 1990 was about $140 \mathrm{~g} /$ person per week, about $40 \mathrm{~g}$ of which was oil-rich fish (see p. S8) consumed mainly as canned or processed products (British Nutrition Foundation, 1993). Fish consumption levels in the UK remained remarkably stable throughout the 1980s (British Nutrition Foundation, 1993) and are unlikely to have changed much during the 1990 s, although a significant shift in the species consumed in the UK has undoubtedly occurred with salmon and trout forming an increasing proportion of the total intake at the expense of cod.

\section{$n$-6 AND $n-3$ POLYUNSATURATED FATTY ACIDS AS ESSENTIAL NUTRIENTS IN HUMAN DIETS}

Fish protein is, of course, of high nutritional value but in the last two decades emphasis on the nutritional value of fish to vertebrate animals and especially to humans has shifted towards fish oils and specifically towards the long-chain $n-3$ polyunsaturated fatty acids (PUFA) in fish oils, namely docosahexaenoic acid (DHA, 22:6n-3), and eicosapentaenoic acid (EPA, 20:5n-3). The wealth of studies underlying the relatively recent emphasis on n-3 PUFA in nutrition may be summarized as follows (see British Nutrition Foundation, 1992; Sargent \& Henderson, 1995; Sargent et al. 1995a,b).

PUFA of the $n-6$ series have long been known to be essential dietary constituents for man. Specifically, arachidonic acid (AA, 20:4n-6), is essential for numerous bodily functions in all vertebrates so far studied including man. AA can either be consumed directly in the diet or formed within the body from linoleic acid (LA, 18:2n-6), itself 
consumed in the diet:

$$
\begin{gathered}
\text { linoleic acid } \Rightarrow \text { arachidonic acid } \\
18: 2 n-6 \Rightarrow 20: 4 n-6
\end{gathered}
$$

LA is abundant in nearly all commonly available vegetable oils such as maize, sunflowerseed, safflowerseed and rapeseed oils. The long-chain $n-3$ PUFA DHA and EPA are also essential for many bodily functions in vertebrates including man. These fatty acids can either be delivered directly from the diet or produced within the body from linolenic acid (LNA, 18:3n-3), itself consumed directly in the diet:

$$
\begin{aligned}
& \text { linolenic acid } \Rightarrow \text { eicosapentaenoic acid } \Rightarrow \text { docosahexaenoic acid } \\
& 18: 3 n-3 \quad \Rightarrow \quad 20: 5 n-3 \quad \Rightarrow \quad 22: 6 n-3
\end{aligned}
$$

LNA is present in all green leafy vegetables as a component of chloroplast lipids, with these lipids constituting only a small fraction of green-leaf biomass. With the exception of linseed oil, there are few current commercially available vegetable oils rich in LNA and, even then, such oils including linseed oil are invariably rich also in LA.

The realization that 22:6n-3 and 20:5n-3 are essential for bodily functions came much later than the realization that 20:4n-6 was essential, by which time diets in Western societies contained high levels of $18: 2 n-6$ derived from vegetable oils, low levels of $18: 3 n$ 3 derived from green leafy vegetables, and also low levels of $20: 5 n-3$ and 22:6n-3 derived more-or-less exclusively from fish. The problem with this diet is that the conversion of $18: 2 n-6$ to $20: 4 n-6$ within the body competes with the conversion of $18: 3 n-3$ to $20: 5 n-3$ and thence to $22: 6 n-3$. Consequently, a diet rich in $18: 2 n-6$ but poor in $18: 3 n-3$ generates a relative excess of $20: 4 n-6$ in the body and a relative deficiency of $20: 5 n-3$ and 22:6n-3. The relative excess of 20:4n-6 generates an excess of highly biologically active metabolites of $20: 4 n-6$, collectively termed eicosanoids, which are involved in a range of 'stress-related' disorders including cardiovascular and inflammatory conditions. Production of eicosanoids from $20: 4 n-6$ is normally depressed by $20: 5 n-3$ so that an excess of 20:4n-6 and a lack of 20:5n-3 results in the excessive production of eicosanoids. As important, 22:6n-3 is essential for proper development of the brain and the eye so that a deficiency of 22:6n-3 during early development, as can happen in premature infants fed on formula feeds which lack this fatty acid as distinct from mother's milk which contains this fatty acid, can result in visual and cognitive subnormalities.

There are two practical outcomes to this. First, what constitutes an optimal or even a desirable dietary $n$-6 PUFA: $n$ - 3 PUFA ratio in man? The answer is not known with certainty but a value in the region of 5:1 is probably reasonable, whereas a value in the region of 50:1 is undoubtedly excessive. It may be noted here that there is evidence that our early ancestors consumed diets with $n-6: n-3$ ratios approximating to $1: 1$ (Simopolous, 1991) so that the ratio has undoubtedly changed markedly over the centuries and has now veered overmuch towards $n-6$ PUFA. Second, can it be assumed that $18: 2 n-6$ and $18: 3 n-3$ can be converted efficiently in the body to higher C20 and C22 homologues to satisfy tissue requirements? The answer is that there is significant doubt that such conversions can proceed sufficiently rapidly under all conditions and at all times, particularly when there is a high demand for the end-product as occurs during early growth and development. Therefore, under these conditions it is prudent to consume at least some preformed 20:4n-6 and 22:6n-3; hence the recommendation to supplement premature infant formula feeds with these fatty acids. The scientific evidence underlying these considerations has been set out in the British Nutrition Foundation's report on unsaturated fatty acids (British Nutrition 
Foundation, 1992). It is on such evidence that both the British Nutrition Foundation's report and the report of the Cardiovascular Review Group Committee on Medical Aspects of Food Policy (Department of Health, 1994) recommended an increased intake of oily fish rich in $20: 5 n-3$ and $22: 6 n-3$ in the UK diet. These recommendations have been fully justified by continuing scientific research in this field as witnessed by numerous major international conferences, e.g. International Society for the Study of Fats and Lipids (ISSFAL) Conferences in 1995 and 1996 (Various, 1996, 1997), and also by a plethora of scientific publications regularly summarized in the ISSFAL Newsletter, volumes 1-3, 1994-6. There is also increasing emphasis (see the aforementioned international conferences) on the potential beneficial effects of $22: 6 n-3$ in a range of visual and mental disorders. In short, the case that $20: 5 n-3$ and $22: 6 n-3$ can be beneficial in human diets is now undisputed.

\section{FISH AS RICH SOURCES OF $n$ - 3 POLYUNSATURATED FATTY ACIDS: A FUNDAMENTAL DIFFERENCE BETWEEN MARINE AND TERRESTRIAL FOOD PRODUCTION SYSTEMS}

The distinction of fish as pelagic and demersal, referred to earlier in considering the UK catch, broadly translates into oily and non-oily fish. This is because the oil reserves of pelagic fish such as herring, mackerel, capelin, sprats, sardines, pilchards and anchovies are stored chiefly in the fillet (and periviscerally), with oil levels frequently reaching $20 \%$ or more of the wet weight of the fish, whereas the oil reserves of demersal fish such as cod, haddock and whiting are stored in the livers, more than half of whose wet weight can be oil, and not in the flesh. Therefore, cod fillets are not a rich source of oil rich in 20:5n-3 and 22:6n-3, whereas cod liver is a rich source of these fatty acids, as are the fillets of herring, mackerel, sardines etc.

Despite this broad difference in the location of oil reserves in fish tissues, the composition of oils from different species has many features in common, chief of which is a high concentration of $20: 5 n-3$ and $22: 6 n-3$. This comes about because, in terms of fats and oils, marine (and also freshwater) food webs differ fundamentally from current terrestrial agricultural food production systems in Western societies. The latter produce principally animal fats derived largely from ruminants and pigs, together with a range of vegetable-seed oils. Such animal fats are invariably rich in saturated fatty acids, chiefly 16:0 and 18:0. This is because the 18:3n-3 fatty acid present in small but very significant amounts in the green leafy vegetable material consumed by ruminants, and any other PUFA present, is readily and extensively biohydrogenated to $18: 0$ by the rumen microorganisms that degrade plant cellulose to acetate. These processes collectively result in herbivorous ruminants producing body lipids rich in saturated fatty acids. The vegetableseed oils currently produced in very large amounts in Western agriculture are invariably rich in PUFA, chiefly $18: 2 n-6$, and also monounsaturated fatty acids, chiefly oleic acid, 18:1n-9. Thus, current Western terrestrial food production systems generate major quantities of saturated fatty acids from ruminants and major quantities of 18:2n-6 from plant-seed oils.

The natural marine food web contrasts with terrestrial food production systems in that the primary producers in the oceans are unicellular phytoplanktonic protists, mostly algae, that are rich sources of $20: 5 n-3$ and $22: 6 n-3$ as well as a range of other C16 and C18 $n$-3 PUFA (reviewed by Sargent \& Henderson, 1995; Sargent et al. 1996). These phytoplanktonic protists and their constituent $n$-3 PUFA are efficiently harvested by filterfeeding zooplanktonic crustaceans that are in turn efficiently harvested by filter-feeding zooplankton-consuming teleost fish. Biohydrogenation reactions do not occur in the short, 
efficient marine food chains, so that the resulting marine fish oils are rich sources of $n-3$ PUFA, especially 20:5n-3 and 22:6n-3.

\section{n-3 POLYUNSATURATED FATTY ACIDS IN FISH OILS ORIGINATE IN MARINE PHYTOPLANKTON}

The species composition of marine phytoplankton is complex and varies with location and season. Nonetheless, in food webs underlying most major fisheries including those off north west Europe the phytoplankton is frequently dominated by a limited number of species. These include the silicaceous diatoms, various flagellates (the chief of which are dinoflagellates) and two species of haptophyceans (which are also flagellated), namely the coccolithophore Emiliania huxleyi and Phaeocystis pouchetti (van Beusekom \& DielChristiansen, 1993). Marine phytoplankton do not contain large oil reserves in the spring and summer when the cells are rapidly growing and dividing, but they do contain membrane lipids in their frequently large chloroplasts and such lipid constitutes 10-20\% of the cells' dry weights. It is this chloroplast lipid that is very rich in $n$-3 PUFA and the type of PUFA present varies characteristically with species (reviewed by Sargent $e t$ al. 1996).

Thus, the lipids of diatoms contain large quantities of 20:5n-3 with appreciable quantities of C16 n-3 PUFA but negligible amounts of 22:6n-3. In contrast, the lipids of dinoflagellates and other flagellates including Emiliania huxleyi and Phaeocystis pouchetti contain large amounts of $22: 6 n-3$, and also $18: 4 n-3$ and 18:5n-3. Phytoplankton communities are often dominated in early spring by diatoms and in late spring-summer by flagellates including Emiliania huxleyi and Phaeocystis pouchetti. Such phytoplanktonic communities are typical of the natural food of filter-feeding zooplankton and they provide a diet for these small crustaceans rich in long-chain $n$-3 PUFA composed of very substantial amounts of 20:5n-3 and 22:6n-3, the precise proportions of which depend on the species composition of the phytoplankton at any given time.

The precise function 22:6n-3 serves in the limited groups of marine photosynthetic eukaryotes that produce it is not known with certainty. However, we believe that the production of $22: 6 n-3$ by such organisms is related to their being both motile and phototactic (light seeking) (see Sargent et al. 1996). Phototaxis coupled to flagellar motion has obvious advantages for cells in a dilute, frequently nutrient-poor and often turbulent medium, where sinking into deep waters beyond the limits of light penetration is a constant hazard.

\section{$n-3$ POLYUNSATURATED FATTY ACIDS ARE TRANSMITTED FROM PHYTOPLANKTON VIA ZOOPLANKTON TO FISH}

The transmission of fatty acids through marine food webs has recently been reviewed by Sargent \& Henderson (1995) and Sargent et al. (1995b) on which the following account is based. Marine zooplankton retain the $n-3$ PUFA ingested in their phytoplankton diet, mostly $20: 5 n-3$ and $22: 6 n-3$, in the phospholipids of their cellular membranes and they also store these fatty acids in their neutral oil reserves. However, marine zooplankton can produce a range of fatty acids, including the long-chain monounsaturated acids 20:1n-9 and $22: 1 n-11$ that are not present in phytoplankton, and also store these fatty acids in oil reserves. Moreover, the oil reserves of zooplankton can be either triacylglycerols (fatty acids esterified to glycerol) or wax esters (fatty alcohols esterified to fatty acids), the fatty alcohols in the wax esters frequently being $20: 1 n-9$ and $22: 1 n-11$ entities derived from the 
Table 1. Fatty acid composition of various fish oils ( $\mathrm{g} / 100 \mathrm{~g}$ total fatty acids in total lipid)

\begin{tabular}{|c|c|c|c|c|c|c|}
\hline Fatty acid & $\begin{array}{l}\text { Farmed } \\
\text { salmon } \\
\text { flesh* }\end{array}$ & $\begin{array}{l}\text { Oil fed } \\
\text { to farmed } \\
\text { salmon* }\end{array}$ & $\begin{array}{l}\text { Wild } \\
\text { salmon } \\
\text { flesh* }\end{array}$ & Herring $\dagger$ & Capelin $\dagger$ & Anchovy $\dagger$ \\
\hline $14: 0$ & 5 & 5 & 4 & 7 & 7 & 7 \\
\hline $16: 0$ & 16 & 15 & 13 & 13 & 13 & 17 \\
\hline $16: \ln -7$ & 7 & 6 & 4 & 7 & 10 & 9 \\
\hline 18:0 & 3 & 2 & 3 & 1 & 1 & 4 \\
\hline $18: 1 n-9$ & 13 & 10 & 19 & 10 & 14 & 12 \\
\hline $18: 2 n-6$ & 3 & 3 & 1 & 1 & 2 & 1 \\
\hline $18: 3 n-3$ & 2 & 2 & 1 & 1 & 1 & 1 \\
\hline $18: 4 n-3$ & 3 & 5 & 1 & 3 & 4 & - \\
\hline $20: \ln -9$ & 9 & 9 & 12 & 13 & 16 & 2 \\
\hline $20: 5 n-3$ & 7 & 9 & 7 & 6 & 8 & 17 \\
\hline $22: \ln -11$ & 10 & 15 & 11 & 23 & 15 & 2 \\
\hline $22: 6 n-3$ & 12 & 12 & 10 & 6 & 6 & 9 \\
\hline Saturates & 24 & 22 & 20 & 21 & 21 & 28 \\
\hline Monounsaturates & 43 & 42 & 52 & 53 & 55 & 23 \\
\hline$n-3$ PUFA & 28 & 30 & 24 & 16 & 19 & 31 \\
\hline
\end{tabular}

PUFA, polyunsaturated fatty acids.

* J. G. Bell, J. McEvoy and J. R. Sargent, unpublished results; values are means of eight individual fish.

$\dagger$ Data from Sargent \& Henderson (1995) and references cited therein.

corresponding fatty acids. Wax ester formation by marine zooplankton is an adaptation to extreme light regimes in very high (polar) latitudes that determine an abundant but limited seasonal availability of phytoplankton in the brief spring-summer when primary production occurs in these regions. Under these conditions, the zooplankton can accumulate more than $50 \%$ of their dry body weight as oil composed mainly of wax esters. Zooplankton from lower latitudes in more temperate waters accumulate much lower levels of oil containing negligible levels of wax esters, i.e. the total lipid of low-latitude zooplankton contains much higher proportions of phospholipids than is the case for highlatitude zooplankton.

Wax esters ingested by zooplanktonivorous fish are readily digested, assimilated and converted to triacylglycerols with their constituent $20: 1 n-9$ and $22: 1 n-11$ fatty alcohols being reconverted to fatty acids in the process. Thus, the abundant triacylglycerol body oils of zooplankton-consuming fish in relatively high latitudes, e.g. herring, capelin, mackerel, sprats and sand eels, have relatively high proportions of $20: 1 n-9$ and $22: 1 n-11$ fatty acids and relatively low proportions of $n-3$ PUFA in their body triacylglycerol oils, with the proportion of $20: 5 n-3$ often exceeding that of $22: 6 n-3$ (Table 1). Because planktonivorous fish in lower latitudes, e.g. sardines, pilchards and anchovies, do not consume wax-esterrich zooplankton, these fish have lower absolute quantities of triacylglycerol body oils, with these oils having only small proportions of $20: 1 n-9$ and $22: 1 n-11$ fatty acids and, as a consequence, higher proportions of $n$-3 PUFA than high-latitude fish oils, with $20: 5 n-3$ again being present in a higher proportion than 22:6n-3 (Table 1). Thus, a typical fatty acid composition for pilchard oil, i.e. a low-latitude fish oil is ( $\mathrm{g} / 100 \mathrm{~g}$ total fatty acids): $20: 5 n-3$ $17,22: 6 n-39,20: 1 n-95,22: 1 n-113$, whereas a typical composition for capelin oil, i.e. a high-latitude fish oil is (g/100 g total fatty acids): $20: 5 n-3 \quad 8,22: 6 n-3 \quad 6,20: 1 n-9 \quad 17$, $22: 1 n-11$ 14. It is mainly oils of the former type that are selected as supplements for human nutrition such as Maxepa ${ }^{\mathrm{TM}}$ (Seven Seas, Hull, Humberside). It is mainly oils of the 
latter type that are used for producing partially hydrogenated fish oils and also for producing animal feeds including feeds for farmed fish.

\section{TAILORING THE FATTY ACID COMPOSITION OF FISH OILS FOR HUMAN CONSUMPTION}

The differences between the fatty acid composition of high-latitude and low-latitude fish oils described earlier already establish that the fatty acid composition of fish oils is readily influenced by the fatty acid composition of the lipids in the fishes' diets. Consequently, it is easy to alter the fatty acid composition of body oils of farmed fish by altering the fatty acid composition of their dietary lipid (see Sargent, 1995; Sargent \& Henderson, 1995; Sargent et al. 1995a,b). There are, however, limitations to tailoring fish body oil, such limitations being set by the following considerations. First, all marine fish so far studied have lost the ability to convert C18 to C20 and thence to C22 PUFA (Sargent et al. 1995a). Second, marine fish have a strict dietary requirement for high levels of $n-3$ PUFA and almost certainly also for much lower levels of $n-6$ PUFA, with an optimal dietary $n-3$ PUFA: $n-6$ PUFA ratio of about 15:1 (Sargent et al. 1995a). That is, marine fish have a much higher requirement for $n-3$ PUFA than higher terrestrial vertebrates including man. It is because of this high requirement for $n-3$ PUFA, and specifically for the end-products $20: 5 n-3$ and $22: 6 n-3$, that marine fish are invariably fed on diets containing high levels of marine oils, these being the only commercially available source of such fatty acids. In practice, the grade of fish meal commonly used for manufacturing fish feeds contains about $100 \mathrm{~g}$ fish oil $/ \mathrm{kg}$. Such an oil level is usually sufficient in itself for many fish species but it can be supplemented if necessary, to levels up to $300 \mathrm{~g} / \mathrm{kg}$ dry weight of the fish feed, by blending additional fish oil with the fish meal. 'High-energy', i.e. high-oil diets of the latter type are now commonly used in salmon farming.

In contrast to marine fish, many freshwater fish including trout and salmon (salmon have a major seagoing phase in their life history) readily convert C18 PUFA to their C20 and C22 homologues (Sargent et al. 1995a). Moreover, some freshwater fish including tilapia, carp and channel catfish grow readily with dietary $18: 2 n-6$ to $18: 3 n-3$ ratios of $1: 1$ and greater. Even so, the growth performance of such freshwater fish is invariably improved when their diets are supplemented with marine fish oil, i.e. the end-products $22: 6 n-3$ and $20: 5 n-3$ are more efficient growth promoters than the precursor $18: 3 n-3$ and $n-3$ PUFA are more efficient than the $n-6$ PUFA (Sargent et al. 1995a). There is, therefore, a natural preference to farm freshwater fish on diets containing marine fish oil so that the diets of farmed freshwater fish such as trout and eels are composed principally of marine fish meal and marine fish oil. However, the diets of such fish are commonly supplemented, often to a major extent as illustrated by channel catfish diets, by vegetable oils rich in $18: 2 n-6$. These considerations for freshwater fish apply principally to on-growing juvenile fish. They do not necessarily apply to early developing larval fish stages where the requirement for $n-3$ PUFA, especially $20: 5 n-3$ and $22: 6 n-3$ is probably higher than for the juveniles (Sargent, 1995; Sargent et al. 1995a). Certainly, the early larval stages of marine fish have a high and exacting requirement for 20:5n-3 and especially 22:6n-3 (Bell et al. $1995 a$ ).

There is a common misconception that farmed fish in general are not as rich in $n-3$ PUFA as wild fish. This can be the case, e.g. for channel catfish, if the fish are fed on diets rich in vegetable oils and if, for example, soyabean protein is used as a partial replacement for the main fish-meal protein component of conventional fish diet. It is not, however, the case when the fish are fed on diets based largely if not completely on fish meal and fish oil, which is overwhelmingly the case for all marine fish, including salmon, currently farmed in 
Europe including the UK. Thus, in a recent extensive and ongoing survey of salmon farmed in Scotland we have established (Sargent, 1995; J. G. Bell, J. McEvoy and J. R. Sargent, unpublished results) (a) that the diets of the fish invariably contain almost exclusively highgrade fish oil, (b) that there is a strong correlation between the amount of oil deposited in the salmon carcass and the amount of oil present in the diet, up to dietary oil levels of about $300 \mathrm{~g} / \mathrm{kg}$ dry weight, and (c) that the proportions of $20: 5 n-3$ and $22: 6 n-3$ in the oil deposited in salmon fillets are similar to those of wild salmon (see Table 1). In addition, the farmed salmon have levels of the natural pigment astaxanthin and the natural antioxidant $\alpha$ tocopherol entirely comparable with, if not exceeding, those of wild fish. By these criteria farmed salmon are a nutritionally high-quality food for human consumption. Given that salmon can easily be farmed to generate higher levels of oil in their fillets than wild salmon, it is the case that farmed salmon can have greater absolute levels of $n-3$ PUFA in their flesh than wild salmon. We have no direct analytical data currently available for other farmed marine fish species, whether sea bass, turbot or halibut, but the same general conclusion reached for salmon almost certainly holds for these species also, if for no other reason than these species are fed on diets composed principally of fish meal and fish oil.

Thus, by using fish oil as the only source of dietary oil and varying the amount or type of oil in the diet, marine fish can be readily farmed to yield fillets with levels of oil, $22: 6 n-3$ and $20: 5 n-3$ as required to suit consumer demand and human nutritional and health requirements. By adding vegetable oils such as rapeseed oil or linseed oil to the fish feed, it is also easy to enhance, if required, levels of 18:2n-6 and 18:3n-3 in salmon fillets (Bell et $a l$. 1995b). Finally, as an exercise designed to illustrate the possibilities of tailoring flesh lipids of farmed fish to defined ends we have shown that by feeding turbot on borage oil, which contains substantial amounts of $\gamma$-linolenic acid $(18: 3 n-6)$ as well as LA, it is possible to produce fish with enhanced carcass levels of both 18:3n-6 and its bioactive product dihomo- $\gamma$-linolenic acid, 20:3n-6 (Bell et al. 1995c). Such exercises, however, are designed to understand how to control levels of given fatty acids in farmed fish flesh accurately and reliably. They should not obscure the main and important speciality of fish in human nutrition as an efficient vehicle for delivering health-promoting long-chain $n-3$ PUFA in the diet. Wild fish are very efficient in this respect and fish farmed under modern practices are at least as efficient. Modern fish farming, and especially marine fish farming, has much to offer, whether nutritionally, economically or ethically, for optimizing the exploitation of limited global marine resources of fish meal and fish oil.

\section{REFERENCES}

Barlow, S. M. \& Pike, I. H. (1994). Upgrading the uses of lower species to provide a source of omega-3 fatty acids in the human diet. Omega-3 News 9, 5-8.

Bell, J. G., Tocher, D. R., MacDonald, F. \& Sargent, J. R. (1995a). Diets rich in eicosapentaenoic acid and $\gamma-$ linolenic acid affect phospholipid fatty acid composition and production of E1, E2 and E3 in turbot (Scophthalamus maximus), a species deficient in $\Delta-5$ fatty acid desaturase. Prostaglandins, Leukotrienes and Essential Fatty Acids 53, 279-286.

Bell, J. G., Tocher, D. R., MacDonald, F. \& Sargent, J. R. (1995b). Effects of borage oil [enriched in $\gamma$-linolenic acid, 18:3(n-6)] or marine oil [enriched in eicosapentaenoic acid, 20:5(n-3)] on growth, mortalities, liver histopathology and lipid composition of juvenile turbot (Scophthalamus maximus L.). Fish Physiology and Biochemistry 14, 373-383.

Bell, M. V., Batty, R. S., Dick, J. R., Fretwell, K., Navarro, J. C. \& Sargent, J. R. (1995c). Dietary deficiency of docosahexaenoic acid impairs vision at low light intensities in juvenile herring (Clupea harengus, L.). Lipids 30, 443-449.

British Nutrition Foundation (1992). Unsaturated Fatty Acids. Nutritional and Physiological Significance. Report of the British Nutrition Foundation's Task Force. London: Chapman and Hall.

British Nutrition Foundation (1993). Nutritional Aspects of Fish. Briefing Paper no. 10. London: British Nutrition Foundation. 
Department of Health (1994). Nutritional Aspects of Cardiovascular Disease. Report on Health and Social Subjects no. 46. London: H.M. Stationery Office.

James, D. G. (1994). Fish as food: present utilisation and future prospects. Omega-3 News 9, 1-4.

Pauly, D. \& Christensen, V. (1995). Primary production required to sustain global fisheries. Nature 374, 255257.

Sargent, J. R. (1995). (n-3)Polyunsaturated fatty acids and farmed fish. In Fish Oil Technology, Nutrition and Marketing, pp. 67-94 [R. J. Hamilton and R. D. Rice, editors]. High Wycombe: P. J. Barnes and Associates.

Sargent, J. R., Bell, J. G., Bell, M. V., Henderson, R. J. \& Tocher, D. R. (1995a). Requirement criteria for essential fatty acids. Symposium of European Inland Fisheries Advisory Committee. Journal of Applied Ichthyology 11, 183-198.

Sargent, J. R., Bell, M. V., Bell, J. G., Henderson, R. J. \& Tocher, D. R. (1995b). Origins and functions of $(n-3)$ polyunsaturated fatty acids in marine organisms. In Phospholipids: Characterisation, Metabolism and Novel Biological Applications, pp. 248-259 [G. Cevc and F. Paltauf, editors]. Champaign, IL: American Oil Chemists' Society Press.

Sargent, J. R., Bell, M. V. \& Henderson, R. J. (1996). Protists as sources of ( $n$-3) polyunsaturated fatty acids for vertebrate development. In Protistological Actualities. Proceedings of the 2nd European Conference on Protistology and the 8th European Conference on Ciliate Biology, pp. 54-64 [G. Brugerolle and J. P. Mignot, editors]. Available from J. Senaud, Biologie des Protists, 63177 Aubiere Cedex, France.

Sargent, J. R. \& Henderson, R. J. (1995). Marine (n-3) polyunsaturated fatty acids. In Developments in Oils and Fats, pp. 32-65 [R. J. Hamilton, editor]. London: Blackie Academic and Professional.

Simopolous, A. P. (1991). Omega-3 fatty acids in health and disease and in growth and development. American Journal of Clinical Nutrition 54, 438-463.

van Beusekom, J. \& Diel-Christiansen, S. (1993). A Synthesis of Phyto- and Zooplankton Dynamics in the North Sea Environment. Godalming: World Wildlife Fund.

Various (1996). International Conference on Highly Unsaturated Fatty Acids in Nutrition and Disease Prevention, Bethesda, Maryland. Lipids 31, Suppl., S1-S326.

Various (1997). International Conference on Highly Unsaturated Fatty Acids in Nutrition and Disease Prevention, Barcelona, Spain. Lipids (In the Press). 